\title{
PEMBUKUAN DAN PELAPORAN INFORMASI AKUNTANSI KEUANGAN BERBASIS PSAK 45: PADA PANTI ASUHAN AL-AMANAH, PALEMBANG
}

\author{
Rita Martini $^{1{ }^{*}}$, Zulkifli Zulkifli ${ }^{2)}$, Sukmini Hartati ${ }^{3)}$, Rosy Armaini ${ }^{4)}$ \\ ${ }^{1234)}$ Jurusan Akuntansi, Politeknik Negeri Sriwijaya, Palembang \\ *martinirita65@gmail.com
}

\begin{abstract}
This report aims to examine the implementation of non-profit entity financial reporting at Panti Asuhan Al-Amanah, Palembang referring to Pernyataan Standar Akuntansi Keuangan Number 45 (PSAK 45). The data used in this study is the data related to the preparation of financial statements of financial transactions orphanage. The discussion in this report is how the process of recording transactions, the process of over viewing transactions, preparing financial statements of activity reports, statements of financial position, and cash flow statement. Based on the facts obtained, the orphanage has not made a financial report. Results based on the financial statements made, the orphanage decreased net assets in the period of December 2017.
\end{abstract}

Keywords: Financial statement, non-profit entity, PSAK 45

\section{PENDAHULUAN}

Kemunculan entitas nirlaba sebagai salah satu sektor keuangan di Indonesia merupakan hal yang tabu di masyarakat. Organisasi jenis ini adalah organisasi non profit yang menekankan pada pelayanan sebaik-baiknya pada pihak eksternal, misalnya organisasi pelayanan kesehatan, pendidikan, layanan sosial dan keagamaan [1] dan [2]. Semakin maraknya entitas nirlaba yang bermunculan di era sekarang ini mengharuskan adanya akuntabilitas dan transparansi dalam mempertanggung jawabkan hasil kinerja yang telah dilakukan oleh entitas tersebut [3] dan [4].

Banyak sekali kasus yang diakibatkan oleh tidak terbukanya sebuah entitas nirlaba, contohnya kasus Panti Sosial Tresna Werdha di Pare-Pare Sulawesi yang terungkap pada September 2011. Entitas nirlaba ini mengatasnamakan panti untuk meraup keuntungan pribadi bahkan para penghuni panti disuguhi makanan basi oleh pengelola panti dan diberikan tempat huni yang tidak layak tinggal karena dana yang diberikan untuk kebutuhan penghuni panti dialihkan untuk kepentingan pribadi [5].
Begitu juga dengan Panti Asuhan Samuel yang melakukan kekerasan kepada anak asuh serta melakukan kecurangan dalam menggunakan sumbangan donatur [6]. Agar tidak terjadi masalah/kecurangan seperti pada kasuskasus tersebut, sebuah laporan sebagai bentuk pertanggungjawaban entitas nirlaba kepada pihak donatur perlu dibuat [1]; [2]; dan [7].

Menurut PSAK 45, entitas nirlaba memperoleh sumber daya dari sumbangan para anggota dan para penyumbang lain yang tidak mengharapkan imbalan apapun dari organisasi tersebut [8]. Entitas nirlaba memperoleh modal sendiri atau fund capital dengan cara memperbesar surplus yang diperoleh, menerima sumbangan atau bantuan donasi dari individu atau sekelompok masyarakat. Sumbangan atau bantuan donasi perlu dicatat dan dibuatkan laporan agar terjadinya transparansi dan akuntanbilitas dalam mengelola sumbangan atau bantuan donasi tersebut, juga berfungsi sebagai informasi bagi pihak-pihak yang berkepentingan (donatur, pemerintah, dan lain-lain) untuk melihat perkembangan organisasi dan untuk pengambilan keputusan untuk berdonasi [9]; [10]; dan 
[3]. Melihat pentingnya laporan keuangan bagi sebuah entitas khususnya entitas nirlaba, maka perlu ada suatu aturan baku yang mengatur mengenai penyusunan laporan keuangan organisasi nirlaba, IAI mengeluarkan PSAK mengenai organisasi nirlaba yaitu PSAK 45.

Panti Asuhan Al-Amanah merupakan entitas nirlaba yang berada di Kota Palembang dulunya bernama Yayasan Sosial Al-Amanah Panti Asuhan dan Asuhan Luar Panti (foster car) yang mengalami kendala dalam menyusun laporan keuangan berdasarkan PSAK 45 disebabkan kurangnya pemahaman dalam menyusun laporan keuangan [11]. Praktik penyusunan laporan keuangan yang telah dilakukan hanya pada pencatatan arus dana masuk dan keluar, laporan keuangan yang disajikan panti hanya dibuat untuk pertanggungjawaban kepada donatur, namun belum sesuai dengan PSAK 45 sebagai dasar untuk menyusun pelaporan keuangan entitas nirlaba.

Pengelola yayasan berkeinginan untuk menertibkan catatan/pembukuan keuangannya secara praktis namun sesuai dengan acuan yang berlaku. Aturan yang dijadikan acuan dari pemerintah di bidang keuangan yaitu PSAK 45 tahun 2017 [8]. Sumber referensi lain dalam kegiatan ini merujuk pada [9]. Permasalahan utama pengelola yayasan panti asuhan, ingin memahami administrasi pembukuan yang sederhana namun secara komprehensif menggambarkan seluruh aktivitas penggunaan keuangan. Jika tertib pembukuan panti terpenuhi, maka transparansi keuangannya yang selama ini hanya sebagai bentuk sedekah/sumbangan donator akan lebih bermakna sebagai bentuk pertanggungjawaban pengelola.

\section{IDENTIFIKASI MASALAH}

Masalah pokok pada Panti Asuhan Al-Amanah ialah belum menerapkan pelaporan keuangan yang sesuai dengan standar pelaporan keuangan entitas nirlaba mengacu pada PSAK 45, masalah khususnya yaitu:
1. Belum membuat Laporan Aktivitas, sehingga tidak tersedia informasi mengenai pengaruh dan hubungan transaksi dan peristiwa lain yang mengubah sifat aset neto.

2. Belum membuat Laporan Posisi Keuangan, hal ini menyebabkan tidak diketahuinya berapa aset, liabilitas dan aset neto panti asuhan.

3. Belum membuat Laporan Arus Kas, hal ini menyebabkan tidak diketahuinya arus kas masuk dan arus kas keluar yang terjadi pada panti selama periode tertentu.

Tujuan pokok pengabdian ini untuk menerapkan pembukuan dan pelaporan informasi akuntansi keuangan yang sesuai dengan standar pelaporan keuangan entitas nirlaba mengacu pada PSAK Nomor 45. Khususnya bertujuan agar:

1. Panti membuat laporan aktivitas sehingga diperoleh informasi mengenai pengaruh dan hubungan transaksi dan peristiwa lain yang mengubah sifat aset neto.

2. Panti membuat laporan posisi keuangan untuk mengetahui berapa aset, liabilitas dan aset neto panti.

3. Panti membuat laporan arus kas sehingga diketahuiarus kas masuk dan arus kas keluar yang dilakukan panti selama periode tertentu.

\section{METODOLOGI PELAKSANAAN}

Untuk dapat mengatasi identifikasi masalah, mitra diberi pengetahuan melalui ceramah dan pelatihan teknis mengenai akuntansi keuangan. Akuntansi keuangan merupakan cabang akuntansi yang bertujuan umum sebagai panduan dalam pengelolaan transaksi keuangan (pembukuan) sampai pelaporan informasi akuntansi berupa Laporan Keuangan [9]; [10]; dan [8]. Selain itu mitra juga dimotivasi untuk menumbuhkan kepedulian akan penerapan dan pelaporan informasi akuntansi keuangan. Setelah memahami, mitra diminta untuk menerapkan dan membuat laporan keuangan sesuai dengan acuan. 
Metode pelaksanaan program pengabdian ini meliputi:

1. Ceramah. Metode ini dipilih untuk pengetahuan tentang akuntansi keuangan dan membekali peserta agar memiliki pemahaman dan pengetahuan tentang teknis pengelolaan pembukuan dan pelaporan informasi akuntansi keuangan bagi entitas nirlaba.

2. Pelatihan/workshop. Kegiatan ini berupa ketrampilan praktik dalam bentuk pelaporan informasi akuntansi keuangan yang sebenarnya secara fisik.

3. Pendampingan. Mitra juga didampingi dalam pengelolaan pembukuan dan penyusunan informasi akuntansi keuangan mengacu pada PSAK 45 tahun 2017 tentang standar akuntansi keuangan bagi entitas nirlaba.

Langkah-langkah pada kegiatan pengabdian ini sebagai berikut:

1. Mengidentifikasikan pengelolaan pembukuan dan pelaporan informasi akuntansi keuangan,

2. Menelusuri dan membandingkan data transaksi akuntansi, menghitung, dan penyusunan pelaporan informasi akuntansi keuangan,

3. Menyusun kekurangan pengelolaan pembukuan dan pelaporan informasi akuntansi keuangan panti asuhan, lalu membuat laporan keuangan,

4. Menyusun rekomendasi atas perbandingan laporan keuangan panti asuhan dan laporan keuangan.

5. Pendampingan dalam pengelolaan pembukuan.

6. Pendampingan dalam menyusun laporan keuangan.

\section{HASIL DAN PEMBAHASAN}

Panti Asuhan Al-Amanah belum membuat laporan keuangan, panti hanya membuat catatan kas masuk dan kas keluar secara manual, maka dalam penyusunan laporan keuangannya diharapkan mengacu pada standar akuntansi yang berlaku khususnya untuk entitas nirlaba, berdasarkan PSAK 45 [9] dan [8]. Dengan adanya laporan keuangan yang sesuai standar akuntansi, diharapkan pihak panti dapat menilai aset, liabilitas maupun aset neto dan dapat mengatasi masalah keuangan dan lebih memudahkan dalam pengambilan keputusan bagi pihak eksternal dalam perkembangan panti kedepannya [10]; [7]; dan [1].

Pembahasan ini dimulai dari pembuatan daftar perkiraan dan neraca awal panti asuhan. Mencatat seluruh transaksi yang terjadi ke dalam jurnal kas di tangan dan membuatkan jurnal penyesuaian di akhir bulan. Selanjutnya, melakukan pemindahbukuan (posting) seluruh jurnal ke buku besar dan membuatkan neraca lajur berdasarkan angka yang ada pada buku besar tersebut. Hasil proses tersebut dijadikan dasar dalam penyusunan laporan keuangan, berupa laporan aktivitas, laporan posisi keuangan, dan laporan arus kas [9]; [10]; dan [8].

Contoh penerapan pengelolaan pembukuan dan pelaporan informasi akuntansi keuangan pada Panti Asuhan Al-Amanah pada kegiatan pengabdian ini, mengacu pada PSAK 45 tahun 2017 berdasarkan catatan-catatan dan laporan keuangan yang telah dibuat selama bulan Desember 2017.

\subsection{Laporan Aktivitas}

Laporan aktivitas menyediakan informasi mengenai pengaruh transaksi dan peristiwa lain yang mengubah aset neto [9] dan [8]. Laporan aktivitas yang telah dibuat berdasarkan kertas kerja tersaji sebagai berikut: 


\section{Panti Asuhan Al-Amanah, Palembang \\ Laporan Aktivitas}

Untuk Bulan yang berakhir pada 31 Desember 2017

\section{Pendapatan Aset Neto Tidak Terikat PENDAPATAN \\ Pendapatan Donasi \\ Jumlah Pendapatan \\ BEBAN \\ Beban Listrik \\ Beban Konsumsi \\ Beban Perlengkapan \\ Beban Penyusutan Peralatan \\ Beban Penyusutan Bangunan \\ Beban Iuran SPP}

Perubahan Aset Neto yang Tidak Terikat

\section{Jumlah Beban}

Penurunan Aset Neto Tidak Terikat Perubahan Aset Neto Terikat Temporer Penurunan Aset Neto Terikat Temporer Perubahan Aset Neto Terikat Permanen Penurunan Aset Neto Terikat Permanen Total Penurunan Aset Neto

\section{Aset Neto Awal}

Aset Neto Tidak Terikat

Aset Neto Terikat Temporer

Aset Neto Terikat Permanen

Total Aset Neto Awal

Aset Neto Akhir

Aset Neto Tidak Terikat

Aset Neto Terikat Temporer

Aset Neto Terikat Permanen

Total Aset Neto Akhir

Sumber: [12]

Terjadi penurunan nilai aset neto tidak terikat sebesar Rp 1.996.667. Aset neto terikat permanen panti tidak terjadi perubahan, sehingga terjadi penurunan aset neto akhir panti sebesar Rp 1.996 .667$.
Rp $\quad 124.000$

Rp $\quad 1.939 .000$

Rp $\quad 1.388 .000$

Rp $\quad 544.417$

Rp $\quad 656.250$

Rp $\quad 400.000$

Rp $\quad \mathbf{5 . 0 5 1 . 6 6 7}$

Rp (1.996.667)

Rp $\quad-\quad R p$

$\mathrm{Rp}$

$\underline{\mathrm{Rp}}$

$\mathrm{Rp} \quad(1.996 .667)$

Rp $\quad 18.803 .167$

$\underline{\text { Rp 223.125.000 }}$

$\underline{\operatorname{Rp} 241.928 .167}$

Rp $\quad 16.806 .500$

Rp 223.125.000
Rp 239.931.500

$\mathrm{Rp} \quad 3.055 .000$

Rp $\quad 3.055 .000$

\subsection{Laporan Posisi Keuangan}

Laporan posisi keuangan adalah laporan yang berisikan informasi mengenai aset, liabilitas, serta aset neto dan informasi mengenai hubungan di antara unsur-unsur tersebut pada waktu tertentu [9] dan [8]. Laporan posisi keuangan yang perlu buat per 31 Desember 2017 disajikan berikut: 
Panti Asuhan Al-Amanah, Palembang

Laporan Posisi Keuangan

Per 31 Desember 2017 dan Per 30 November 2017

\begin{tabular}{|c|c|c|c|}
\hline & & $31 / 12 / 2017$ & 30/11/2017 \\
\hline \multicolumn{4}{|l|}{ Aset } \\
\hline Kas dan Setara Kas & $\mathrm{Rp}$ & 992.000 & 1.750 .000 \\
\hline \multicolumn{4}{|l|}{ Aset Lancar Lainnya } \\
\hline Perlengkapan-Tidak Terikat & $\mathrm{Rp}$ & 4.429 .000 & 4.467 .000 \\
\hline \multicolumn{4}{|l|}{ Aset Tidak Lancar } \\
\hline \multicolumn{4}{|l|}{ Aset Tetap } \\
\hline Peralatan & $\mathrm{Rp}$ & 27.011 .000 & 27.011 .000 \\
\hline Akm. Peny. Peralatan & $\mathrm{Rp}$ & $(14.709 .250)$ & $\mathrm{Rp} \quad(14.164 .833)$ \\
\hline \multicolumn{4}{|l|}{ Aset Tetap Terikat Permanen } \\
\hline Tanah & $\mathrm{Rp}$ & 189.000 .000 & Rp 189.000 .000 \\
\hline Bangunan & $\mathrm{Rp}$ & 157.500 .000 & Rp 157.500 .000 \\
\hline Akm. Peny. Bangunan & $\mathrm{Rp}$ & $(124.031 .250)$ & Rp (123.375.000) \\
\hline Jumlah Aset & $\mathbf{R p}$ & 240.191.500 & Rp 242.188.167 \\
\hline \multicolumn{4}{|l|}{ Liabilitas dan Aset Neto } \\
\hline Hutang SPP Anak Asuh & $\mathrm{Rp}$ & 260.000 & 260.000 \\
\hline Jumlah Liabilitas & $\mathbf{R p}$ & 260.000 & 260.000 \\
\hline \multicolumn{4}{|l|}{ Aset Neto } \\
\hline Aset Neto Tidak Terikat & $\mathrm{Rp}$ & 16.806 .500 & 18.803 .167 \\
\hline Aset Neto Terikat Temporer & - & & - \\
\hline Aset Neto Terikat Permanen & $\mathrm{Rp}$ & 223.125 .000 & Rp 223.125 .000 \\
\hline Jumlah Aset Neto & $\mathbf{R p}$ & 239.931.500 & Rp 241.928 .167 \\
\hline $\begin{array}{l}\text { Jumlah Liabilitas dan Aset } \\
\text { Neto }\end{array}$ & $\mathbf{R p}$ & 240.451 .500 & Rp 242.448 .167 \\
\hline
\end{tabular}

Sumber: [12]

Berdasarkan laporan posisi keuangan panti, terjadi penurunan aset neto panti di bulan Desember sebesar Rp 1.996.667, penurunan sebesar $0,99 \%$. Penurunan ini disebabkan karena beban lebih besar daripada pendapatan donasi yang diterima pada periode Desember 2017.

\subsection{Laporan Arus Kas}

Laporan arus kas merupakan laporan yang menginformasikan perubahan dalam penyusunan laporan keuangan sebagai akibat dari kegiatan usaha pembelanjaan dan investasi selama periode bersangkutan [9] dan [8]. Laporan arus kas yang perlu dibuat untuk bulan Desember 2017 tersaji berikut: 
Panti Asuhan Al-Amanah, Palembang

Laporan Arus Kas

Untuk Bulan yang Berakhir pada 31 Desember 2017

\begin{tabular}{|c|c|c|c|}
\hline \multicolumn{4}{|l|}{ Aliran Kas dari Aktivitas Operasi } \\
\hline $\begin{array}{l}\text { Kas yang diterima dari donasi } \\
\text { Kas yang dibayarkan untuk pembelian } \\
\text { perlengkapan }\end{array}$ & $\begin{array}{l}\mathrm{Rp} 3.055 .000 \\
\mathrm{Rp}(1.350 .000)\end{array}$ & & \\
\hline Kas yang dibayarkan untuk listrik & $\mathrm{Rp} \quad(124.000)$ & & \\
\hline Kas yang dibayarkan untuk konsumsi & $\operatorname{Rp}(1.939 .000)$ & & \\
\hline $\begin{array}{l}\text { Kas yang dibayarkan untuk iuran SPP } \\
\text { Kas bersih yang diterima (digunakan) untuk } \\
\text { aktivitas operasi }\end{array}$ & $\underline{\operatorname{Rp} \quad(400.000)}$ & $\mathrm{Rp}$ & 758.000 \\
\hline \multicolumn{4}{|l|}{ Aliran Kas dari Aktivitas Investasi } \\
\hline $\begin{array}{l}\text { Pembelian Peralatan } \\
\text { Kas bersih yang diterima (digunakan) untuk } \\
\text { aktivitas Investasi }\end{array}$ & $\underline{\mathrm{Rp}}$ & $\mathrm{Rp}$ & 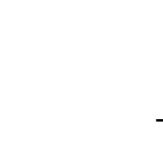 \\
\hline \multicolumn{4}{|l|}{ Aliran Kas dari Aktivitas Pendanaan } \\
\hline $\begin{array}{l}\text { Kas yang diterima dari waqaf } \\
\text { Kas bersih yang diterima (digunakan) untuk } \\
\text { aktivitas Pendanan }\end{array}$ & $\underline{\mathrm{Rp}}$ & $\mathrm{Rp}$ & \\
\hline $\begin{array}{l}\text { Kenaikan (penurunan) bersih dalam kas dan } \\
\text { setara kas }\end{array}$ & & $\mathrm{Rp}$ & 758.000 \\
\hline Kas awal per 1 Desember 2017 & & $\mathrm{Rp}$ & 1.750 .000 \\
\hline Kas akhir per 31 Desember 2017 & & $\mathbf{R p}$ & 992.000 \\
\hline
\end{tabular}

Sumber: [12]

Berdasarkan laporan arus kas panti, terjadi penurunan aliran kas neto dari aktivitas operasional sebesar Rp 758.000. Kas awal per 1 Desember 2017 sebesar Rp 1.750.000, sehingga kas akhir per 31 Desember 2017 menjadi Rp 992.000.

\section{KESIMPULAN}

Panti Asuhan Al-Amanah merupakan salah satu bentuk entitas nirlaba yang berfungsi sebagai penyelenggara pelayanan sosial kepada anak-anak terlantar dan kurang mampu belum melakukan penerapan pelaporan keuangan yang sesuai dengan standar yaitu PSAK 45 tahun 2017.

Berdasarkan hasil kegiatan pengabdian yang telah dilaksanakan dapat disimpulkan: 1) mitra termotivasi untuk menerapkan akuntansi keuangan sesuai dengan standar akuntansi keuangan yang berlaku, dan 2) mitra mendapatkan pemahaman dan pendampingan dalam pengelolaan pembukuan dan pelaporan informasi akuntansi keuangan. Kegiatan dimulai dari penjelasan mengenai pemahaman akan siklus akuntansi, sampai pendampingan penyajian laporan informasi akuntansi keuangan mengacu pada PSAK 45 tahun 2017.

Untuk mendapatkan hasil yang lebih optimal, pelatihan dan pendampingan dalam pengelolaan pembukuan dan pelaporan informasi akuntansi keuangan sebaiknya dilaksanakan secara berkesinambungan dan rutin. Kegiatan serupa juga sebaiknya melibatkan lebih banyak panti asuhan, agar lebih merata dan mendapatkan hasil yang lebih menyeluruh.

\section{UCAPAN TERIMA KASIH}

Penulis mengucapkan terima kasih kepada pimpinan Politeknik Negeri 
Sriwijaya, Palembang. Juga kepada semua pihak yang telah membantu dan berpartisipasi mulai dari persiapan proposal, pelaksanaan, penyelesaian pelaporan kegiatan, hingga tersusunnya artikel ini.

\section{DAFTAR PUSTAKA}

[1] N. C. Yuliarti, "Studi penerapan PSAK 45 Yayasan Panti Asuhan Yabappenatim Jember," Jurnal Akuntansi Universitas Jember, vol. 12, no. 2, pp. 58-73, December 2014.

[2] R. S. Janis and N. S. Budiarso, "Analisis penerapan PSAK No. 45 tentang pelaporan keuangan entitas nirlaba pada Jemaat Gmist Pniel Biau Kab, Kep. Sitaro," Jurnal Accountability, vol. 6, no. 1, pp. 103111, 2017.

[3] I. Fahmi, Analisis kinerja keuangan, Jakarta: Bumi Aksara, 2012.

[4] Kemensos, "Kementerian Sosial," 2018.

[5] Scribd.com, "Kondisi-Panti-SosialTresna-Werdha-Di-Pare," 2018.

[6] Nabilanaradjalazuardi.blogspot.co.id. "penganiayaan-panti-asuhan-samuel," 2018.
[7] D. A. Rizky and Y. Y., "Analisis penerapan PSAK No. 45 pada Yayasan Masjid Al-Falah Surabaya, vol. 2, no. 7, pp. 1-17, 2013.

[8] DSAK-IAI, Pelaporan keuangan entitas nirlaba, pernyataan standar akuntansi keuangan (PSAK) No. 45, Jakarta: DSAK-IAI, 2017.

[9] I. Bastian, Akuntansi yayasan dan lembaga publik, Jakarta: Erlangga, 2007.

[10] S. S. Harahap, Akuntansi sosial ekonomi dan akuntansi Islam, Jakarta: Bumi Aksara, 2008.

[11] Indonesia, Undang-undang nomor 18 tahun 2014 tentang Yayasan, 2014.

[12] R. Martini, Zaliah and H. Winarko, "Pengelolaan Pembukuan dan Pelaporan Informasi Akuntansi Keuangan Berbasis PSAK 45 pada Panti Asuhan Al-Amanah, Palembang, "PPPM Politeknik Negeri Sriwijaya, Palembang, 2018. 